\title{
SCANNING SPEED INFLUENCE ON THE PHYSICAL PROPERTIES OF LASER METAL DEPOSITION TITANIUM ALLOY
}

\author{
R. M. Mahamood ${ }^{1, *}$, J. O. Aweda' ${ }^{2}$, K. R. Ajao ${ }^{3}$, S. AbdulKareem ${ }^{4}$ and H. A. Ajimotokan ${ }^{5}$ \\ 1,23,4,5 DEPARTMENT OF MECHANICAL ENGINEERING, UNIVERSITY OF ILORIN, ILORIN, KWARA STATE. NIGERIA \\ Email addresses: ${ }^{1}$ mahamoodmr2009@gmail.com, ${ }^{2}$ jacobaweda@gmail.com, ${ }^{3}$ ajaomech@gmail.com, \\ 4sulkarm@yahoo.com, ${ }^{5}$ hajims@unilorin.edu.ng
}

\begin{abstract}
The most commonly used aerospace titanium alloy, Ti6Al4V, was deposited on Ti6A14V plate of dimension $72 \times 72 \times 5 \mathrm{~mm}$. The laser power of $3 \mathrm{~kW}$, powder flow rate of $1.44 \mathrm{~g} / \mathrm{min}$ and gas flow rate of $4 \mathrm{l} / \mathrm{min}$ were used throughout the deposition process. The transverse/ scanning speed was varied between 0.005 to $0.095 \mathrm{~m} / \mathrm{sec}$ according to established result of the preliminary study that produces full dense and pore free deposits. The mass of the deposited powder was obtained by weighing the substrate before the deposition and reweighing after the deposition. The substrate and the deposits were thoroughly cleaned using wire brush and acetone to remove unmelted powder particles from the surface of the substrate and the deposit. The height and width of the deposits were measured with Venier Caliper and the material efficiencies were determined using developed equations. The objective of this research is to determine the influence of the scanning speed on the material efficiency and deposit height in laser metal deposition of titanium alloyTi6Al4V. The results of this study showed that, for the set of processing parameter used in this study, the optimum scanning speed was at $0.015 \mathrm{~m} / \mathrm{sec}$ with the optimum material utilization efficiency of $83.33 \%$ and the deposition height of $1.09 \mathrm{~mm}$.
\end{abstract}

Keywords: Additive manufacturing, Laser metal deposition (LMD), Material efficiency, Titanium alloy

\section{INTRODUCTION}

LASER Metal Deposition (LMD) is an additive manufacturing method that produces component by building it layer by layer directly from three dimensional CAD model [1]. LMD belongs to the directed deposition class of additive manufacturing technology based on the recent grouping done by ISO committee additive manufacturing standard [2]. Manufacturing near-net shape parts by LMD through the building layer by layer offer great advantage that includes: time saving, weight saving and overall cost saving when compared with the traditional manufacturing methods $[3,4]$. A component that needs to be broken down into various parts and then later assembled in traditional manufacturing process can be produced in one single piece using the LMD process. This will eliminate various steps of joining and fastening that required to assemble the broken down parts in the traditional manufacturing technique thereby help to reduce the manufacturing time and the overall cost of the part. The most important thing to the transportation industries such as the automobile and the aerospace industries is the weight saving that is achieved through the elimination of extra weights that are usually coming from bolt, nut, and rivets that are used during the assembly process. The use of LMD for the production of aerospace and automobile parts does not only reduce the cost of producing these parts but it will also help to reduce the fuel consumption because of overall weight reduction that will be achieved. Laser metal deposition process also offer an excellent advantage over other additive manufacturing techniques in that it can be used to repair high valued component parts which were prohibitive or difficult to repair and are discarded in the past [5]. This is one of the reasons why LMD is an important research area [5-7] and also this technology is very important for manufacturing and repair of aerospace parts.

Ti6Al4V is the most commonly produced titanium alloy and also the most commonly used titanium alloy in the aerospace industry [8]. Ti6Al4V offer excellent properties $[9,10]$ that make them most sorted material in aerospace, chemical, defense, energy industry etc. The use of titanium is still limited to high valued components because of the high cost of the material and difficulty in machining. The use of laser metal deposition process to produce titanium alloy parts is an excellent alternative to traditional techniques. A number of studies has appeared in the literature on LMD for the fabrication of titanium

${ }^{*}$ Corresponding author, tel: $+234-803-374-4353$ 
and titanium ally composite materials [11-15].Additive manufacturing is generally cost effective to produce parts because the unused materials can be reused. The reuse of titanium alloy is impossible because of the high affinity of the metal to oxygen pickup at high temperature [16]; this makes the study of material efficiency an important one because of the high cost of the material.

In this study, effect of laser transverse speed or scanning speed on the deposit height and material efficiency is investigated. The result of this study will provide an informed decision on the choice of processing parameter that maximizes the use of material while maintaining metallurgical integrity and minimum dilution.

\section{MATERIALS AND METHODS}

The materials and methods are subdivided into four sections namely: materials and equipment, laser metal deposition process, material efficiency determination and macrostructure and microstructure examinations.

\subsection{Materials and equipment}

Laser metal deposition process was achieved with $4.0 \mathrm{~kW}$ fiber delivered Nd: YAG laser with coaxial nozzles carried and controlled by Kuka robot available at the center for scientific and industrial research (CSIR) National Laser Center in Pretoria South Africa. The powder was delivered through argon gas and $5 \mathrm{~mm}$ thick Ti6Al4V plate with area $72 \times 72 \mathrm{~mm}$ of $99.6 \%$ purity was used as substrate for the deposition. The schematic diagram of the laser metal deposition process is shown on Figure 1. The Ti6Al4V powder used in this study has a particle size range between 150-200 $\mu \mathrm{m}$. Prior to the deposition process the substrate was sandblasted, degreased with acetone (a solvent) and dried. The sandblasting was performed to roughen the surface of the substrate in order to aid the laser absorption process.

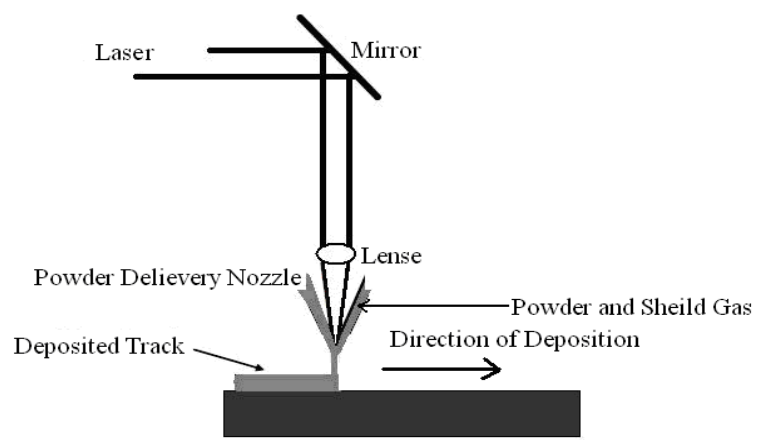

Figure 1: Schematics of Laser Metal Deposition Process

\subsection{Laser Metal Deposition Process}

To achieve the deposition processing parameter used in this study, a set of preliminary experiments was conducted to establish process window in which fully dense deposition without porosity and good metallurgical integrity was obtained. The laser focal length was maintained at a distance of $195 \mathrm{~mm}$ above the substrate at a spot size (laser diameter) of $2 \mathrm{~mm}$. The laser power of $3 \mathrm{~kW}$, powder flow rate of $1.44 \mathrm{~g} / \mathrm{min}$ and gas flow rate of $4 \mathrm{l} / \mathrm{min}$ were maintained throughout the deposition process. The scanning speed of whose effect was investigated was varied between $0.005 \mathrm{~m} / \mathrm{sec}$ and $0.095 \mathrm{~m} / \mathrm{sec}$. a total of ten (10) deposits were made on the substrates of single track $60 \mathrm{~mm}$ long each using the processing parameters in Table 1.The single track is useful to study the deposition geometry which can be translated to multiple track deposition.

Table 1: Processing parameter (Laser power $=3.0 \mathrm{~kW}$ and Gas flow rate $=41 / \mathrm{min}$ )

\begin{tabular}{cc}
\hline Sample Label & Scanning speed $(\mathrm{m} / \mathrm{sec})$ \\
\hline A & 0.005 \\
B & 0.015 \\
C & 0.025 \\
D & 0.035 \\
E & 0.045 \\
F & 0.055 \\
G & 0.065 \\
H & 0.075 \\
I & 0.085 \\
J & 0.095 \\
\hline
\end{tabular}

\subsection{Material Efficiency Determination}

Before the start of deposition, the mass of the substrate was taken using digital balance. After deposition of each track, the deposit and the substrate were cleaned with wire brush and acetone to remove all unmelted powder particles on the substrate and the deposit, and then reweighed to know the mass of actual powder deposited. The height and the width (see Figure 2.) of the deposit was taken using Vernier Caliper. The material efficiency was determined using the following equations (1-4).

$$
\begin{aligned}
& m_{P_{f}}=m_{S_{f}}-m_{S_{o}} \\
& S_{S}=L / T_{D} \text { and } T_{D}=\frac{L}{S_{S}} \\
& m_{P_{o}}=\left(P_{F R} \times T_{D}\right) \div 60 \\
& \mu=\left(m_{P_{f}} / m_{P_{o}}\right) \times 100
\end{aligned}
$$

Where: $m p_{f}(\mathrm{~g})$ is the mass of powder deposited as obtained from equation 1. $m_{S_{0}}(\mathrm{~g})$ is the mass of the substrate before deposition process. $m_{S_{f}}(\mathrm{~g})$ is the mass of substrate after deposition. $\mathrm{S}_{\mathrm{S}}(\mathrm{m} / \mathrm{sec})$ is the scanning speed. $\mathrm{T}_{\mathrm{D}}$ (sec) is the time taken for the deposition. $\mathrm{L}(\mathrm{mm})$ is the length of each track which is $60 \mathrm{~mm}$. $m p_{o}$ (g/sec) is the mass of powder delivered during deposition as obtained from equation 3. $P_{\mathrm{FR}}$ is the powder flow rate in $\mathrm{g} / \mathrm{min}$. $\mu$ is the powder efficiency.

\subsection{Macrostructure and Microstructure Examinations} The samples were laterally sectioned and prepared for optical microscopy using standard metallurgical 
techniques. The macrostructure and microstructure were studied to know the metallurgical integrity of the deposits.

\section{RESULTS AND DISCUSSION}

\subsection{Results}

The morphology of the powder used is shown in Figure 3 as viewed under optical microscope and the particle size distribution analysis is shown in Figure 4. The microstructure of the substrate is shown in Figure 5. The material efficiencies for each of the deposits at various processing parameters (see Table 1) were determined using equations (1) to (4). The processing parameters, the measured height and width of the deposits and the calculated efficiencies are presented in Table 2 . The plots of the material efficiency and the deposition height against the scanning speed (as depicted in Figure 2) is shown in Figure 6, the curves are fitted using appropriate curve fitting tools in Microsoft Excel. Figure 7 shows the Macrostructure of the deposit and the substrate while Figure 8 shows the microstructure of the fusion zone to study the metallurgical integrity of the deposit.

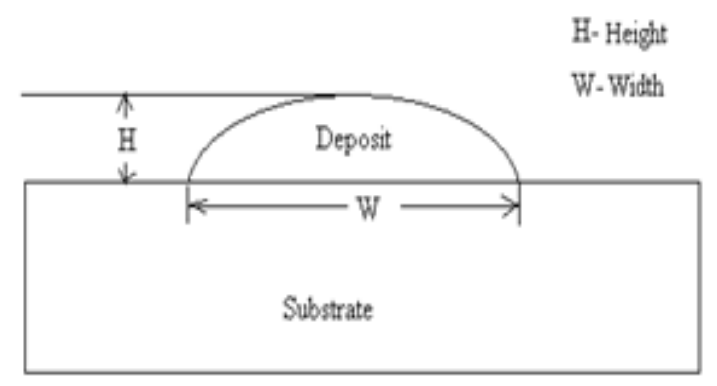

Figure 2: Height and width measurement of the Deposit

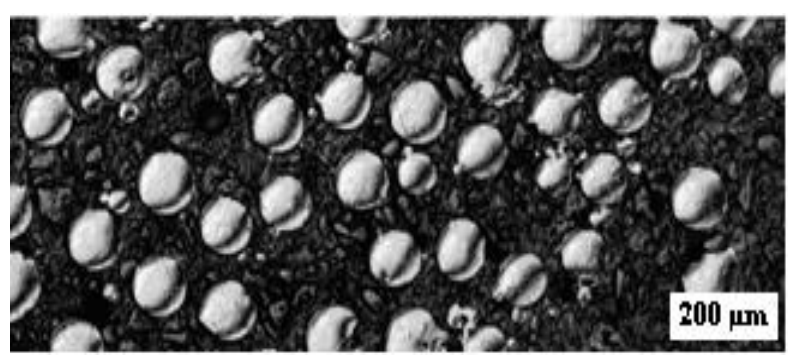

Figure 3: Morphology of Ti6Al4V powder

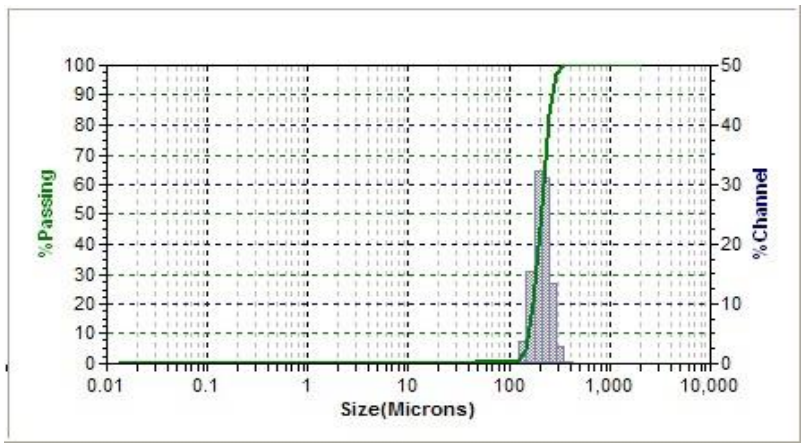

Figure 4: Particle size analysis of the Ti6Al4V powder
Table 2: Results showing track heights, widths and material efficiency (Laser power $=3.0 \mathrm{~kW}$, Power flow rate $=1.44 \mathrm{~g} / \mathrm{min}$ and Gas flow rate $=4 \mathrm{l} / \mathrm{min}$ )

\begin{tabular}{ccccccc}
$\begin{array}{c}\text { Sample } \\
\text { Designati } \\
\text { on }\end{array}$ & $\begin{array}{c}\text { Scanni } \\
\text { ng } \\
\text { Speed } \\
(\mathrm{m} / \mathrm{Sec})\end{array}$ & $\begin{array}{c}m_{P_{0}} \\
(\mathrm{~g} / \mathrm{se} \\
\mathrm{c})\end{array}$ & $\begin{array}{c}m_{P_{f}} \\
(\mathrm{~g} / \mathrm{se} \\
\mathrm{c})\end{array}$ & $\begin{array}{c}\text { Deposit } \\
\text { ed } \\
\text { Track } \\
\text { Width } \\
(\mathrm{mm})\end{array}$ & $\begin{array}{c}\text { Deposit } \\
\text { ed } \\
\text { Track } \\
\text { Height } \\
(\mathrm{mm})\end{array}$ & $\begin{array}{c}\text { Powder } \\
\text { Efficien } \\
\text { cy } \mu \\
(\%)\end{array}$ \\
\hline A & 0.005 & 0.288 & 0.16 & 5.9 & 1.23 & 55.56 \\
B & 0.015 & 0.096 & 0.08 & 4.3 & 1.07 & 83.33 \\
C & 0.025 & 0.058 & 0.04 & 3.1 & 0.4 & 69.44 \\
D & 0.035 & 0.041 & 0.03 & 2.9 & 0.36 & 72.92 \\
E & 0.045 & 0.032 & 0.02 & 3.4 & 0.18 & 62.50 \\
F & 0.055 & 0.026 & 0.02 & 3.0 & 0.42 & 76.39 \\
G & 0.065 & 0.022 & 0.02 & 2.56 & 0.28 & 90.28 \\
H & 0.075 & 0.019 & 0.01 & 2.56 & 0.16 & 52.08 \\
I & 0.085 & 0.017 & 0.01 & 2.52 & 0.18 & 59.03 \\
J & 0.095 & 0.015 & 0.01 & 2.50 & 0.08 & 65.97 \\
\hline
\end{tabular}

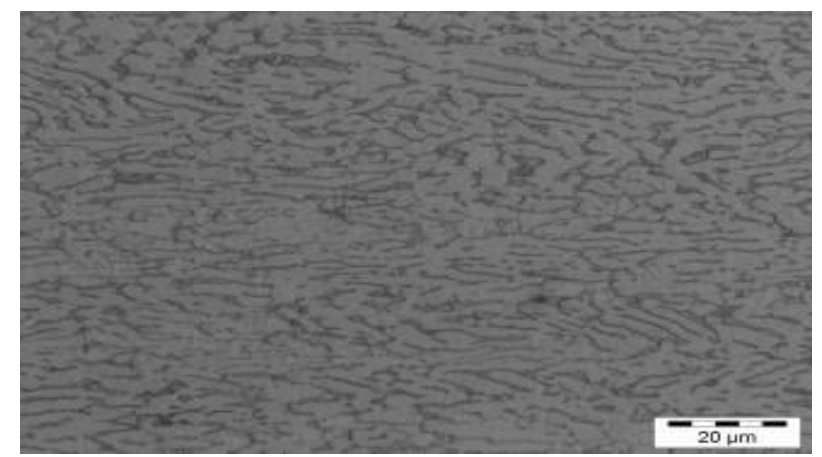

Figure 5: Microstructure of the substrate

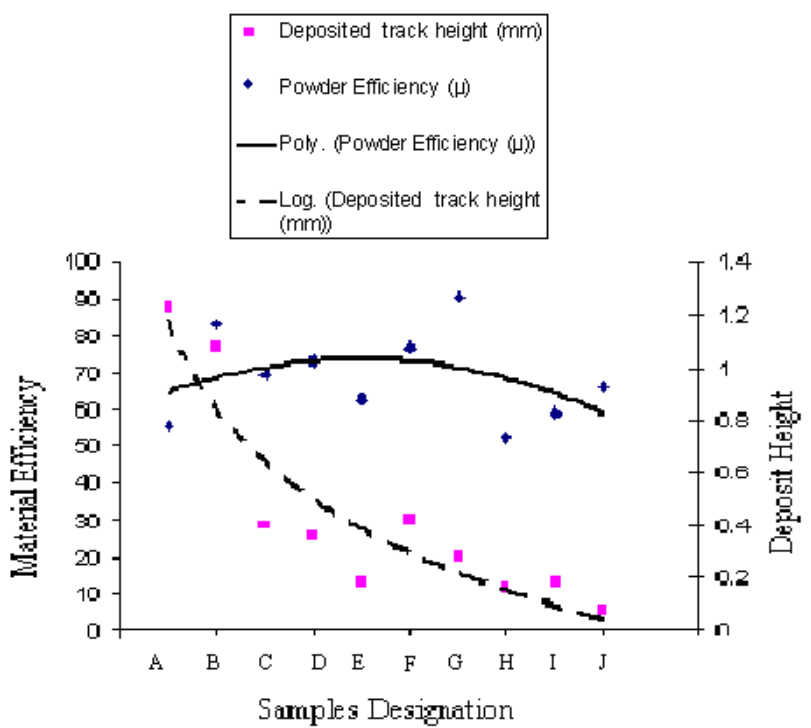

Figure 6: Variation of the material efficiency and the deposit height against the scanning speed

\subsection{Discussion of Results}

It can be seen from the graph that the deposition height tend to decrease when the scanning speed was increased, this is as a result of less powder being delivered as the deposition time decreases. Also the time for the laser material interaction decreases as the scanning speed increases. The deposition track width was seen to decrease as the scanning speed was increased this is because the dilution rate which is proportional to the 
track with is reduced with an increased in the scanning speed. The scanning height was also found to decrease as the scanning speed was increasing. This was as a result of the reducing powder mass that was delivered into the melt pool as a result of reducing laser material interaction time. The material efficiency of sample B was found to increase when compared to that of the sample A although the track width and the track height were found to decrease, this is because, for sample $\mathrm{A}$, the laser material interaction time $\left(\mathrm{T}_{\mathrm{D}}\right)$ is 12 seconds (using equation 2) while the $\mathrm{T}_{\mathrm{D}}$ for sample $\mathrm{A}$ is 4 seconds; The high laser material interaction time allows a lot of powder to be deposited during this process and just a little above halve of the powder was melted by the available laser power. That was why the material efficiency was lower than for sample B. The similar result was observed in sample $G$ when it is compared to sample F. The increase in the material efficiency was as a result of lesser laser material interaction time in sample $G$ that results in proper utilization of the delivered powder during the deposition process. The material efficiency on the other hand increases initially and then decreases with the maximum efficiency at scanning speed of $0.065 \mathrm{~m} / \mathrm{sec}$. this can be attributed to the fact that as scanning speed increases initially more powders are melted effectively until it reaches maximum at the scanning speed of $0.065 \mathrm{~m} / \mathrm{sec}$ and then as the scanning speed increases further there is less time to melt the powder. From Figure 6, the optimum material efficiency is at around the scanning speed of about $0.015 \mathrm{~m} / \mathrm{sec}$.

The macrostructures shown in Figure 7 show that the deposits are sound and the columnar prior beta grains are seen in all the samples with no visible pours. To further confirm the metallurgical integrity of the deposits, the microstructures shown in Figure 8 further confirm there is no porosity and all the deposits are of good metallurgical bonding. Grains in the fusion zone are continuous with the basket weave seen in all the samples which confirms that the materials at this region are fully melted which is consistent with the literature $[17,18]$.

\section{CONCLUSIONS}

Ti6Al4V powder was deposited on Ti6Al4V substrate at varying scanning speed while maintaining laser power, powder flow rate and gas flow rate at constant values of 3 $\mathrm{kW}, 1.44 \mathrm{~g} / \mathrm{min}$ and $4 \mathrm{l} / \mathrm{min}$ respectively. The range of scanning speed of 0.005 to $0.095 \mathrm{~m} / \mathrm{sec}$ that was used in this study was selected based on the result of preliminary experiment that establishes processing window of fully dense deposit without porosity and with good metallurgical bonding. The effect of these scanning speeds on the material deposition efficiency, deposit height, and deposition width were studied extensively. The following conclusions are drawn from the study:
- The optimum scanning speed in this study is approximately $0.015 \mathrm{~m} / \mathrm{sec}$ with the optimum deposition height of $1.09 \mathrm{~mm}$ and deposition efficiency of about $83.33 \%$.

- This scanning speed will keep the material utilization on the high side while minimizing the dilution rate.

\section{REFERENCES}

[1] Toyserkani, E. and Khajepour, A. "A Mechatronics Approach to Laser Powder Deposition Process", Mechatronics, Vol. 16, Number 10, pp 631-641. 2006.

[2] Scott, J., Gupta, N., Wember, C., Newsom, S., Wohlers, T. and Caffrey, T. (2012). "Additive manufacturing: status and opportunities", Science and Technology Policy Institute, Available from:

https://www.ida.org/stpi/occasionalpapers/papers/A M3D 33012 Final.pdf (Accessed on 11 July) 2012.

[3] Irwin, P. A. "Rapid Growth of Additive Manufacturing Disrupts Traditional Manufacturing Process", Press release, 2012, available at http://exone.com/sites/default/files/media/ExOne_Laun ch _Press_Release.pdf, accessed online on 20th July 2012.

[4] Campbell, T., Williams, C., Ivanova, O., Garrett, B.“Could 3D Printing Change the World? Technologies, Potential, and Implications of Additive Manufacturing", Strategic Foresight Report, Available at: http://www.acus.org/files/publication pdfs/403/10171 1_ACUS_3DPrinting.PDF, accessed online on 21st July 2012. 2011.

[5] Pinkerton, A. J., Wang, W. and Li, L.“Component Repair Using Laser Direct Metal Deposition", Proc. IMechE Part B: J. Engineering Manufacture, vol. 222, pp 827-836. 2008,

[6] TWI, "Laser Metal Deposition" Available at http://www.twi.co.uk/technologies/welding-coating-andmaterial-processing/additive-manufacture/laser-metaldeposition/ accessed online on 24th July 2016. $2000 .$.

[7] Donachi, M.J. Titanium-A technical guide, 2nd ed.Metals Park, OH: ASM International, 2000.

[8] Esmailian, M. and Mehrvar, M. "Investigation of the effect of AL203 powder in Electro Discharge Machining for Titanium alloys", ICME, vol. 9, 200, pp 549-557.

[9] Cai Z., Nakajima H., Woldu M., Berglund A., Bergman M., Okabe T. "In Vitro Corrosion Resistance of Titanium Made using Different Fabrication Methods", Biomaterials, Vol. 20, Number 2, pp 183-190. 1999.

[10] Wang Z. M. and Ezugwu E. O. "Titanium Alloys and Their Machinability a Review". Journal of Materials Processing Technology,, pp 68-162. 1997.

[11] Mahamood, R. M., Akinlabi, E. T., Shukla, M. and Pityana, S, "Characterization of Laser Deposited TI6Al4V/TiC Composite Powders on A Ti6Al4V Substrate, Laser in Engineering, 2014.

[12] Mahamood, R. M., Akinlabi, E. T., Shukla, M. and Pityana, S."Characterizing the Effect of Laser Power Density on Microstructure, Microhardness, And Surface Finish of Laser Deposited Titanium Alloy", Journal of Manufacturing Science and Engineering, Vol. 135, Number 6, doi: 10.1115/1.4025737. 2013, 
[13] Mahamood, R. M. and Akinlabi, E. T. "Laser Metal Deposition of Functionally Graded Ti6Al4V/TiC", Materials \& Design, Vol. 84, pp 402-410. 2015.

[14] Akinlabi, E. T., Mahamood, R. M., Akinlabi, S. A. (Eds.) "Advanced Manufacturing Techniques Using Laser Material Processing”, Hershey, PA: IGI Global, 2016.

[15] Mahamood, R. M."Laser Metal Deposition Process", Advanced Manufacturing Techniques Using Laser Material Processing, pp. 46-59, 2016.

[16] Qu J., Blau P. J., Watkins T. R., Cavin O. B., Kulkarni N. S. "Frictionand Wear of Titanium Alloys Sliding against
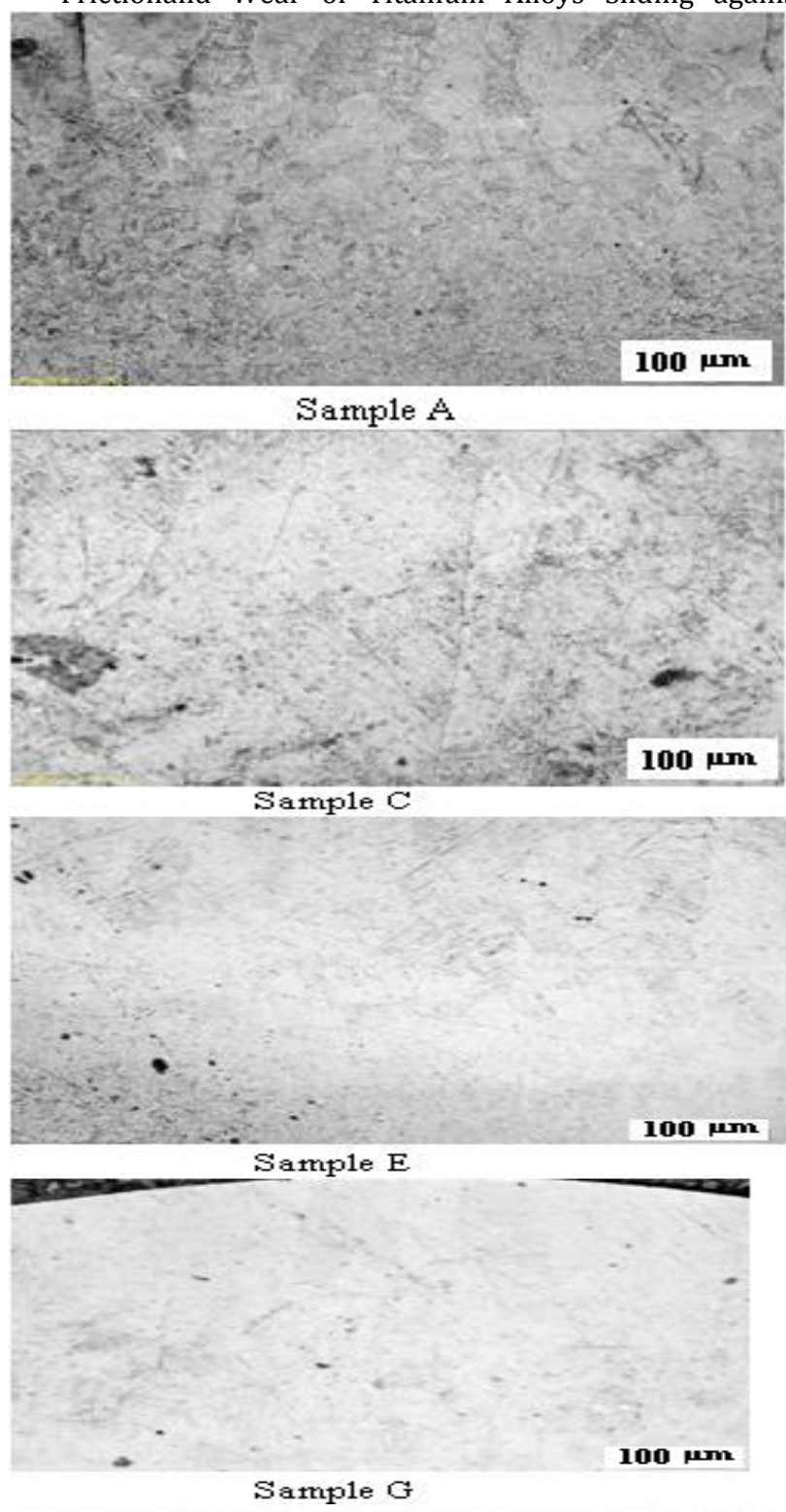

$100 \mathrm{~mm}$

Sample I

Figure 7: The macrostructure of the samples A to J showing the deposit layer and the substrate

Metal, Polymer, and Ceramic Counterfaces", Wear, Vol. 258, pp 1348-1356. 2005.

[17] Lu, Y., Tang, H.B., Fang, Y. L., Liu, D. and Wang, H. M. "Microstructure Evolution of Sub-Critical Annealed Laser Deposited Ti-6Al-4V Alloy", Materials and Design, Vol. 37, pp 56-63. 2012.

[18] Brandl, E., Michailov, V. Viehweger, B. and Leyens, C."Deposition of Ti-6Al-4V using laser and wire, part I: Microstructural properties of single beads", Surface \& Coatings Technology, Vol. 206, pp 1120-1129. 2011.
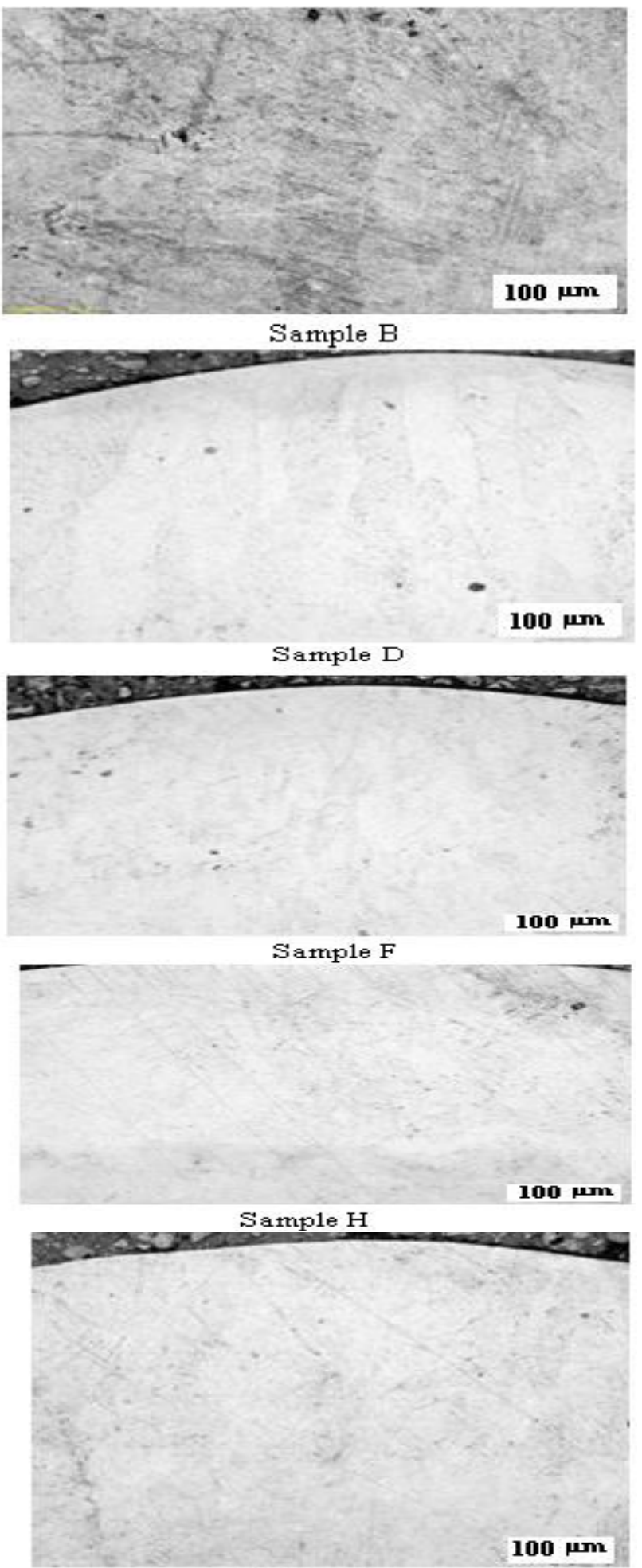

Sample J

$100 \mathrm{~mm}$ 


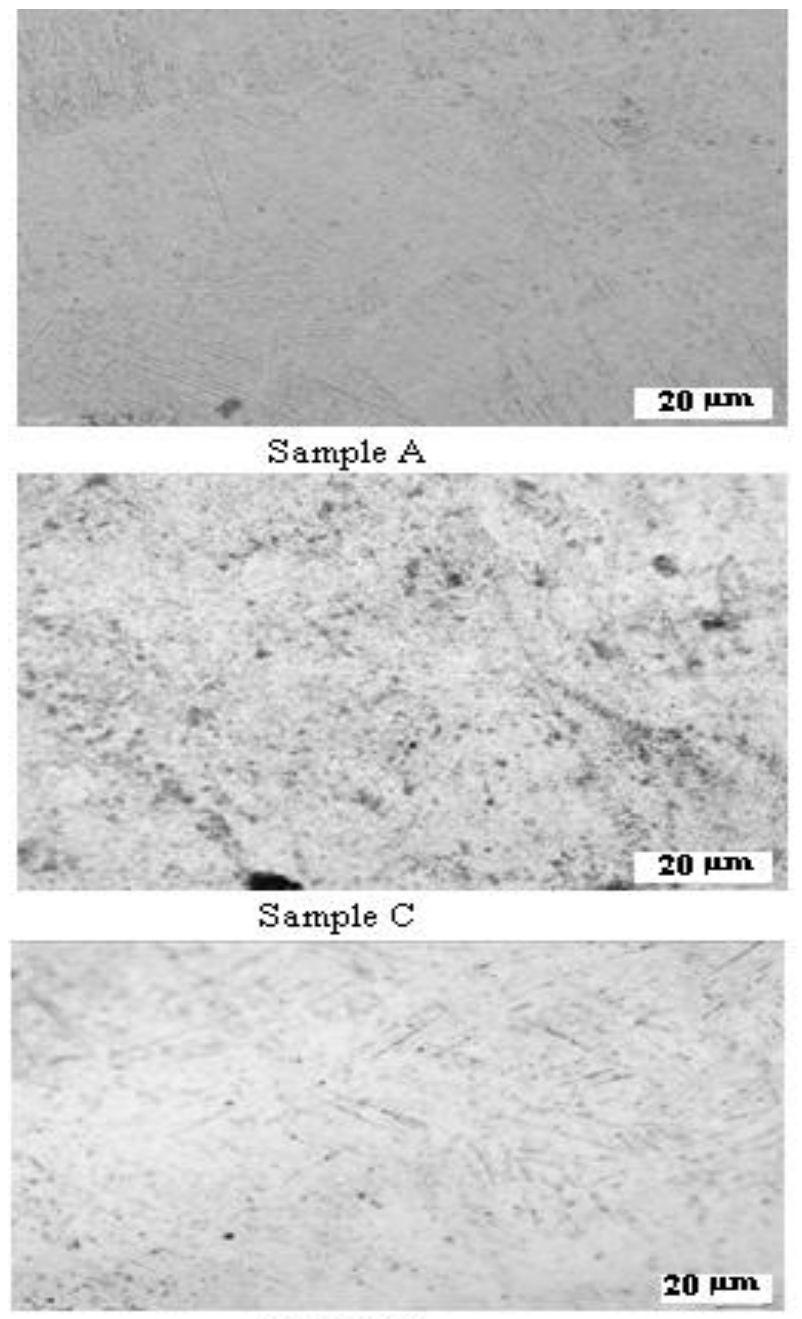

Sample E
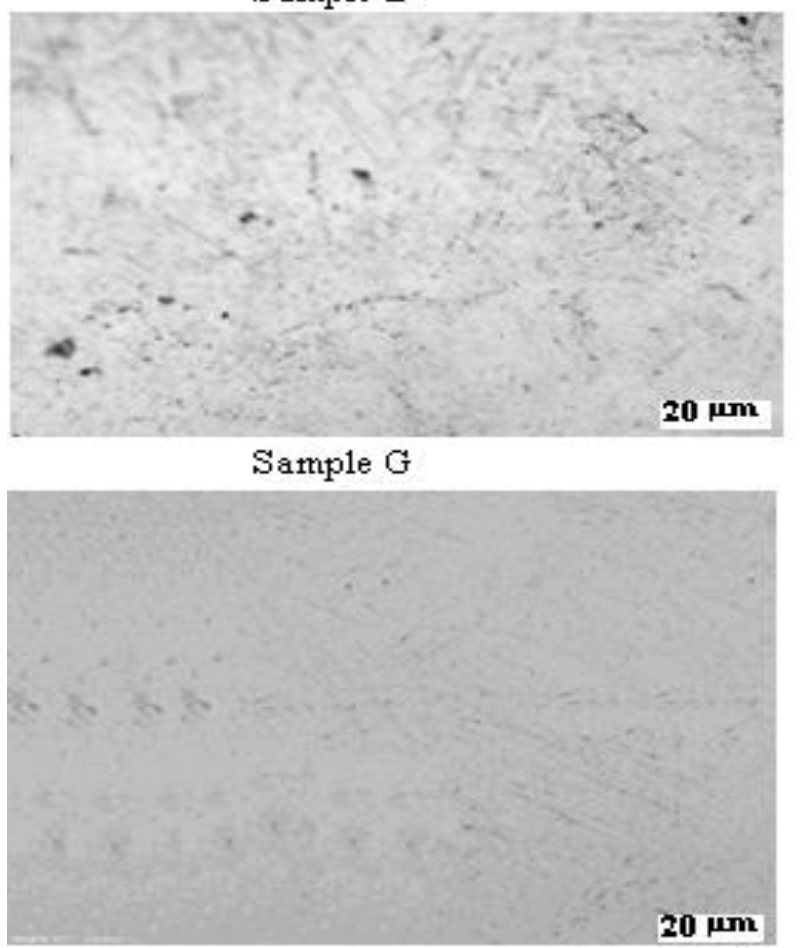

Sample I

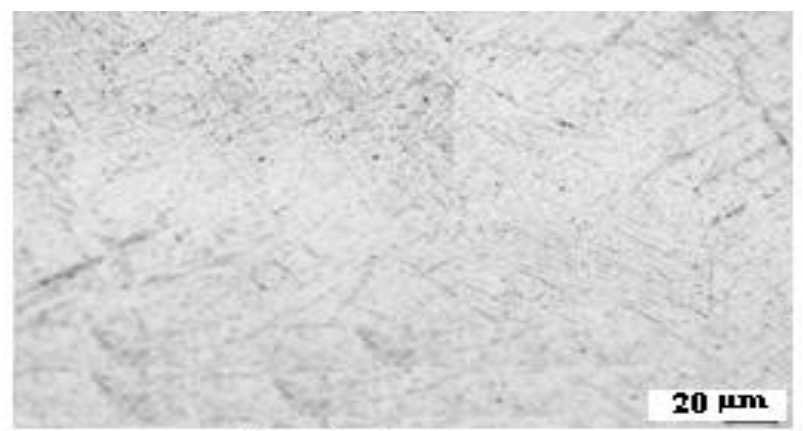

Sample B
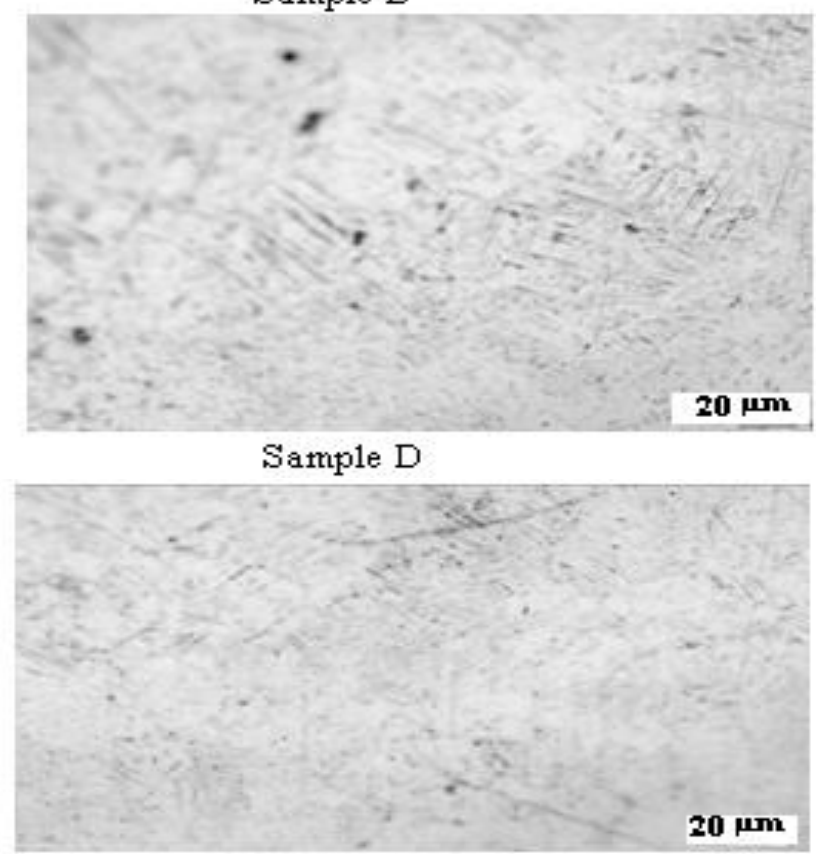

Sample F

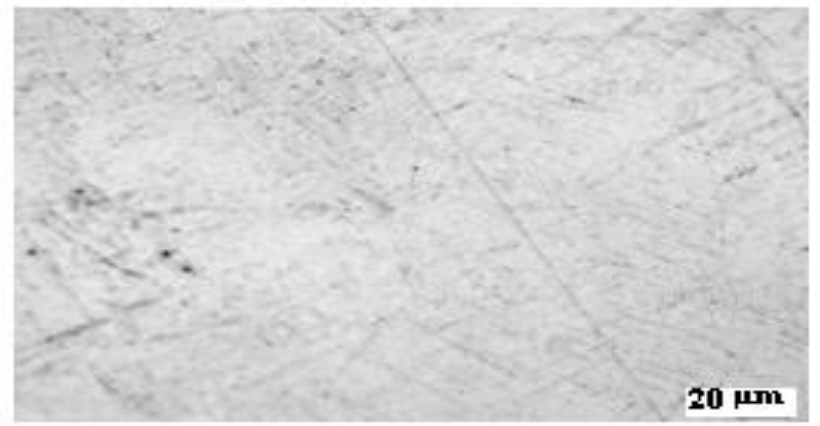

Sample H

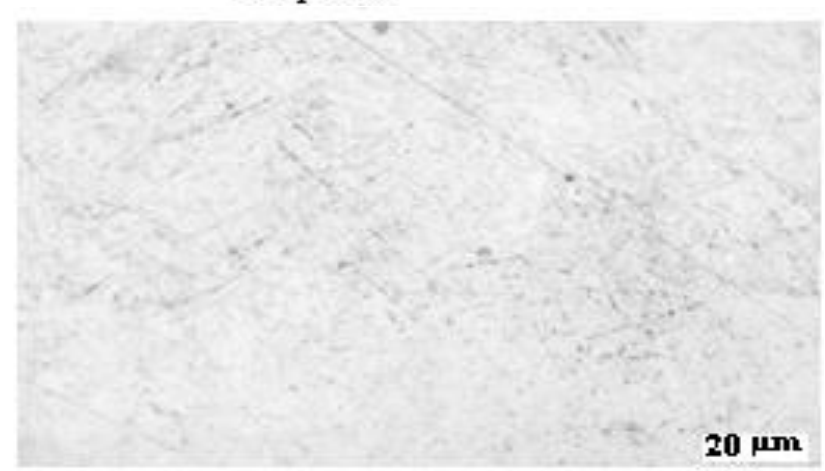

Sample J

Figure 8: The microstructure of the samples A to J showing the fusion zone between the deposit and the substrate 